\title{
Higher Suicide Intent in Patients Attempting Suicide With Violent Methods Versus Self-Poisoning
}

\author{
A Prospective Study From Norway \\ Per Sverre Persett ${ }^{1}$, Øivind Ekeberg, ${ }^{2,3}$, Dag Jacobsen ${ }^{1,4}$, Mari Asphjell Bjornaas ${ }^{1}$, and \\ Hilde Myhren ${ }^{1}$
}

\author{
1Department of Acute Medicine, Oslo University Hospital, Norway \\ ${ }^{2}$ Divisions of Mental Health and Addiction, Oslo University Hospital, Norway \\ ${ }^{3}$ Department of Behavioral Sciences in Medicine, University of Oslo, Norway \\ ${ }^{4}$ Institute of Clinical Sciences, University of Oslo, Norway
}

\begin{abstract}
Background: Suicidal intent for patients attempting suicide using violent methods (VMs) is assumed to be higher than for those using self-poisoning (SP), which may explain the higher mortality observed in follow-up studies. However, this has not been studied prospectively. Aims: We aimed to compare patients attempting suicide using VMs with those using SP regarding suicidal intent, suicidal ideation, depression, and hopelessness during hospital stay and after 1 year. Methods: Patients hospitalized after suicide attempt by VMs $(n=80)$ or SP $(n=81)$ completed the Beck scales for Suicide Intent, Suicide Ideation, Depression Inventory, and Hopelessness on admission and at the 12-month follow-up. Results: On admission, those using VMs had higher suicidal intent than those using SP ( $M=16.2$ vs. 13.3, $p<.001)$, but lower depression scores ( $M=22.2$ vs. $26.8, p<.05)$. No significant differences were found in suicidal ideation $(M=20.1 \mathrm{vs.} 23.1)$ or hopelessness $(M=10.1 \mathrm{vs.} 11.9)$. At 12 -month follow-up, depression scores decreased significantly for both groups, while hopelessness decreased only for the SP group. Limitations: The statistical power achieved was lower than intended. Conclusion: The higher levels of suicidal intent, but lower levels of depression, may indicate more impulsivity among people attempting suicide using VMs. Suicidal ideation was relatively stable.
\end{abstract}

Keywords: depression, emergency department, hopelessness, suicidal intent, violent methods

In suicide risk assessment, higher levels of suicidal intent are usually associated with a higher risk of fatal outcomes. Knowledge of means, availability, and social factors are also crucial for the choice of method and vary worldwide (Sun \& Jia, 2014; Witt et al., 2019). Haw et al. suggested a higher suicidal intent for patients attempting suicide using more violent methods (VMs) than those using self-poisoning (SP; Haw et al., 2015). Retrospective studies indicate that suicide attempts with VM are associated with high suicidal intent (Harriss et al., 2005) and a higher risk of later suicide compared with SP (Runeson et al., 2010).

Suicidal ideation (Beck et al., 1993) involves thinking about, considering, or planning suicide. These thoughts that may subsequently lead to devastating actions and suicide. Suicidal ideation is considered a major risk factor for suicide in psychosis (Courtet, 2018) and other psychiatric disorders (Nordentoft et al., 2011). Suicidal intent and suicidal ideation are associated with a desire for death
(Klonsky et al., 2016) and are essential in the assessment of future risk (Suominen et al., 2004).

In patients diagnosed with a psychotic or affective disorder, suicide attempts involving hanging, drowning, or firearms are associated with a higher risk of later suicide than those involving SP (Runeson et al., 2010). These patients have a higher risk for suicide in the first year after hospital attendance (Cooper et al., 2005; Hawton et al., 2007). Addressing depression and perceived hopelessness is, therefore, important (Woodford et al., 2019). In some patients, the risk remains high for years, or even for a lifetime (Bjornaas et al., 2009; Runeson et al., 2010). Suicidal intent, suicidal ideation, depression, and hopelessness are contributing factors that may increase the risk of suicide and are important considerations in improving the assessment and treatment of patients attempting suicide (Hawton \& van Heeringen, 2009). Suicidal intent and hopelessness have not been studied as much as other validated 
predictors of suicide risk in VM groups. However, these risk factors have been studied thoroughly in SP groups (Bjornaas et al., 2010; Grimholt et al., 2017).

\section{Aims}

The aims of this study were to compare patients who have attempted suicide using VM with patients who have done so using SP, focusing on the intent to die prior to admission, and to explore suicidal ideation, depression, and hopelessness during the hospital stay and at follow-up after 1 year.

\section{Method}

This was a prospective multicenter cohort study of patients who attempted suicide and were admitted to hospitals in Norway (Persett et al., 2018), and it provides data from hospitalization and a 12-month follow-up.

\section{Participants}

Patients aged 18-80 years admitted to medical departments (between December 2010 and April 2015) after a suicide attempt by VM were invited to participate. We defined VM as all methods other than poisoning (Stenbacka \& Jokinen, 2015). Patients admitted for SP within a period of \pm 3 months, matched for gender and age, were included for comparison (Persett et al., 2018). While the initial aim was to include 100 patients in the VM group within 2 years, recruitment ended after 4.5 years, with 80 patients in the group. It was more difficult than anticipated to include patients attempting suicide by VM due to fewer inpatients than expected, and very few patients (as low as one) were recruited at some of the collaborating hospitals and departments.

The original cohort included 161 patients: 80 with VM (63\% males, $M_{\text {age }} 43$ years) and 81 with SP (47\% males, $M_{\text {age }} 42$ years), mostly from Oslo University Hospital (91\% at admission, $87 \%$ at 12 -month follow-up). The other patients were recruited from Akershus University Hospital, Haukeland University Hospital, Innlandet Hospital Trust, Stavanger University Hospital, and Tromsø University Hospital. Patients who had died or could not be traced (i.e., unknown phone number or address) were excluded. Although 115 patients fulfilled the inclusion criteria for the follow-up study, only 31 (56\%) of the 55 eligible patients in the VM group and $30(50 \%)$ patients in the SP group responded.
Overall, ten deaths, seven in the VM group (five suicides) and three in the SP group (no suicides), were registered during the follow-up period (see Figure 1). The deceased all had higher scores for suicide intent, suicide ideation, and depression at baseline than the living participants (mean score 18.4 vs. $14.5, p<.05,23.0$ vs. $21.3, p=$ .58 , and 25.9 vs. $24.5, p=.73$, respectively). For hopelessness, the deceased scored lower at baseline (mean score 9.7 vs. $11.1, p=.48$ ).

Although only those patients with permanent addresses were included, unforeseen life events affected follow-up, including no response by telephone, no valid telephone number, or no updated registered address. Some patients agreed to further participation, but their forms were autoreturned by mail with unknown or incorrect addresses $(n=$ $36)$, or they did not return the questionnaire $(n=48)$. Six of the 161 patients declined to fill out the questionnaires. The sociodemographic distribution was equivalent in both groups at the two measurement times. Age at follow-up was the age registered at baseline (see Table 1). Scores for suicidal ideation, depression, and hopelessness were higher for those participants who did not respond (Table 2).

Classification of diagnostic groups was conducted during the hospital stay or using previous diagnoses stated in their medical records. Diagnoses used were the $F$ diagnoses obtained from the International Classification of Diseases 10 system and identified in 152 of 161 patients. More than one diagnosis was common $(n=63)$, and patients were classified depending on the diagnoses recorded in the following order: F20-29 psychosis $(n=15), \mathrm{F} 60-69$ personality disorders $(n=33)$, F30-39 affective disorders $(n=$ 58), F10-19 substance-use disorders $(n=40)$, and F40-43 anxiety disorders $(n=6)$. As participants with anxiety disorders were only a small group, their data were not included in the final analysis. At baseline, the total number of diagnoses did not differ between the groups. The most common combined diagnoses observed were substance abuse and affective disorders. There were no statistically significant differences in the distribution of psychiatric diagnoses at baseline or at follow-up (Persett et al., 2018).

\section{Measures}

The Suicide Intent Scale (SIS), a 15-item instrument designed to measure the actual aspects of a suicide attempt, was completed during the clinical interview (Bedrosian \& Beck, 1979). Responses were coded (0-2 scale), and SIS scores ranged from 0 (low intent) to 30 (high intent; Samuelsson et al., 2006). The 19-item Beck Scale for Suicide Ideation (SSI) is a self-report instrument where the patient rates severity on a three-point scale (scored 0-2; 


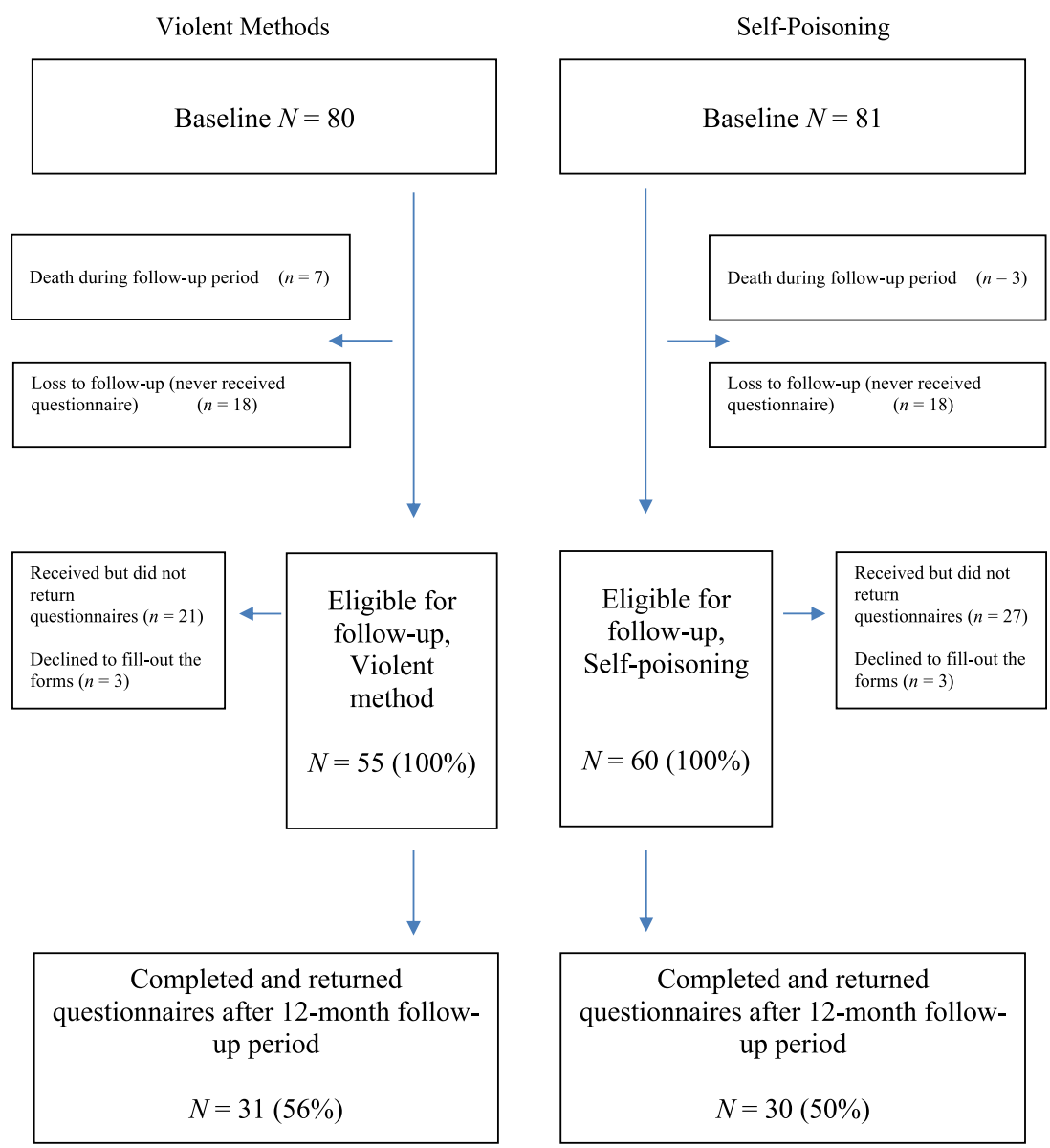

Figure 1. Flowchart for patients using violent methods and self-poisoning in suicide attempts.

Beck et al., 1993). If both Items 4 and 5 are scored as 0 , the patient does not respond to the next 14 items addressing suicide planning and attitude. At baseline, 37 patients in the VM group and 32 in the SP group started completing the SSI form. At follow-up, 13 in the VM group and 12 in the SP group commenced with the form. The Beck Depression Inventory (BDI) is a 21-item questionnaire (scored 0-3) measuring severity of depressive symptoms. Scores of 19-29 indicate moderate depression and 30-63 indicate severe depression (Beck et al., 1993). The Beck Hopelessness Scale (BHS) has been described as the most consistent instrument to predict suicide (Bedrosian \& Beck, 1979; Sidley et al., 1999), consisting of 20 true/false questions. Scores of 0-3 indicate very mild feelings of hopelessness, 4-8 indicate mild feelings, 9-14 indicate moderate feelings, and scores of $>14$ indicate severe feelings of hopelessness (Sidley et al., 1999). All questionnaires used were validated forms translated into Norwegian.

\section{Data Analysis}

Demographics and clinical data are presented as mean values with $S D$ or $95 \%$ CIs or frequencies, unless stated otherwise. Differences in continuous normally distributed variables such as SIS, SSI, BDI, and BHS in the two groups were examined using independent-sample $t$ tests. Pairedsample statistics were used to compare continuous normally distributed variables at the two time points. Low numbers (less than ten) are presented as medians and 25\% and $75 \%$ percentiles or $95 \%$ CI. Mann-Whitney $U$ tests were used to compare two independent groups at the same time point, and Wilcoxon signed-rank tests were used to measure changes within groups at baseline and follow-up. The level of statistical significance was set at $p<.05$. IBM SPSS Statistics for Windows (Version 25; IBM SPSS, Armonk, NY, USA) was used to perform the statistical analyses.

\section{Ethics}

The Norwegian Regional Ethics Committee and the Data Protection Officer at Oslo University Hospital approved the study (REK: 2010/1487). All patients were informed about the aims of the study and signed a written consent form. Evaluations were conducted shortly before hospital discharge and after the 
Table 1. Sociodemographic variables at baseline and 12-month follow-up for violent method and self-poisoning suicide attempts

\begin{tabular}{|c|c|c|c|c|}
\hline \multirow[b]{2}{*}{ No. of patients } & \multicolumn{2}{|c|}{ Baseline } & \multicolumn{2}{|c|}{ 12-month follow-up } \\
\hline & $\begin{array}{c}\text { Violent } \\
\text { methods } \\
n=80\end{array}$ & $\begin{array}{c}\text { Self- } \\
\text { poisoning } \\
n=81\end{array}$ & $\begin{array}{c}\text { Violent } \\
\text { methods } \\
n=31\end{array}$ & $\begin{array}{c}\text { Self- } \\
\text { poisoning } \\
n=30\end{array}$ \\
\hline \multicolumn{5}{|l|}{ Gender (\%) } \\
\hline Male & $50(63)$ & $38(47)$ & $21(68)$ & $11(37)$ \\
\hline Female & $30(37)$ & $43(53)$ & $10(32)$ & $19(63)$ \\
\hline Age, years M (SD) & 41 & 42 & 43 & 45 \\
\hline Male & $43(17)$ & $45(18)$ & $44(17)$ & $57(18)$ \\
\hline Female & $38(14)$ & $39(16)$ & $41(14)$ & $39(15)$ \\
\hline \multicolumn{5}{|l|}{ Marital status \% } \\
\hline Single & 48 & 42 & 39 & 37 \\
\hline $\begin{array}{l}\text { Married/ } \\
\text { cohabitant }^{\text {a }}\end{array}$ & 40 & 41 & 39 & 40 \\
\hline Separated & 9 & 16 & 19 & 20 \\
\hline Widow/widower & 3 & 1 & 3 & 3 \\
\hline \multicolumn{5}{|l|}{ Living conditions \% } \\
\hline Living alone & 46 & 37 & 48 & 30 \\
\hline With others ${ }^{b}$ & 54 & 63 & 52 & 70 \\
\hline \multicolumn{5}{|l|}{ Educational status \% } \\
\hline Primary school & 20 & 20 & 23 & 20 \\
\hline High school & 51 & 44 & 52 & 40 \\
\hline College/university & 29 & 36 & 25 & 40 \\
\hline \multicolumn{5}{|l|}{ Employment status \% } \\
\hline Working & 18 & 22 & 16 & 26 \\
\hline Unemployed & 16 & 22 & 10 & 17 \\
\hline Other ${ }^{c}$ & 66 & 56 & 74 & 57 \\
\hline
\end{tabular}

Note. Composition remained equal according to sociodemographic variables at the two measurement times. alncluding "in a relationship." ${ }^{b}$ Includes with husband/wife or cohabitant or children. "Includes student, disability, retired, sick leave.

psychiatric evaluation of the patients. Participants were given an information leaflet containing the study coordinator's name and phone number, and they were offered guidance and support related to the questionnaires, if needed.

\section{Results}

Patients in the VM group had a significantly higher suicidal intent score on admission than patients in the SP group (SIS M 16.2 vs. $13.3, p<.001$; Table 2). At baseline, the VM group had a significantly lower score for depression (BDI $M 22.2$ vs. $26.8, p<.05)$. There were no significant differences between the groups in suicidal ideation or hopelessness, but there was a trend toward lower scores for these variables in the VM group $(p=.07$ and .06 , respectively).

At the 12-month follow-up, there were no significant differences between the two groups regarding suicidal ideation, depression, or hopelessness. Among patients studied at both time points, suicidal ideation did not change significantly. Depression scores decreased significantly in both groups from baseline to follow-up: The VM group decreased from a $M$ of 20.5-17.6 $(p<.05)$ and the SP group decreased from a $M$ of $26.1-17.3(p<.05)$. Hopelessness was significantly lower at follow-up in the SP group (11.8. vs. 9.3, $p<.05$ ), but not in the VM group (Table 2).

No significant differences were observed between baseline and follow-up for suicidal ideation among the different psychiatric diagnoses (Table 3). Depression decreased significantly at follow-up for patients with personality disorder (95\% CI, 18.7-37.4 vs. 12.1-26.4) and affective disorder (95\% CI, 18.9-28.6 vs. 12.7-22.4), but not for patients with substance use disorder or anxiety disorder. Hopelessness did not change significantly from baseline to follow-up for any subgroups based on psychiatric diagnoses.

\section{Discussion}

Suicidal intent was higher for patients attempting suicide using VM than for patients using SP. However, suicidal ideation did not differ between groups, nor did it change significantly over time. Depression scores were lower in patients using VM than patients using SP. Depression scores decreased over time for both groups and were not related to psychiatric diagnoses. Hopelessness decreased for the SP group over time but remained stable for the VM group.

The high suicidal intent among patients using VM in a suicide attempt is in concordance with previous studies (Harriss et al., 2005), while others also point to a trend for increased suicide intent (Ramanathan et al., 2016). In addition to high intent, access to means is reported to be essential in the choice of a specific method in violent suicide attempts among Swedish males (Stenbacka \& Jokinen, 2015), and access to nonviolent means at home, like pesticides, is less common among those using a VM (Sun \& Jia, 2014). According to Witt et al. (2019), a change of method may occur in subsequent suicide attempts depending on availability, age, and index episode. Others found the methods used in subsequent attempts to be more lethal (Beautrais, 2003). In a systematic review, the classification of risk for repetition was found to be inaccurate, and it was suggested that aftercare should be allocated based on needs rather than risk assessment (Woodford et al., 2019). 
Table 2. Suicidal intent, suicidal ideation, depression and hopelessness in patients who attempted suicide by violent methods or self-poisoning

\begin{tabular}{|c|c|c|c|c|c|c|c|c|c|c|c|c|c|c|c|c|}
\hline \multirow[b]{3}{*}{$\begin{array}{l}\text { Patients, } \\
n=161\end{array}$} & \multicolumn{7}{|c|}{ Baseline } & \multicolumn{7}{|c|}{ 12-month follow-up } & \multirow{2}{*}{\multicolumn{2}{|c|}{$\begin{array}{c}\text { Differences within groups } \\
\text { between baseline and } \\
\text { 12-month follow-up } \\
\text { p value }\end{array}$}} \\
\hline & \multicolumn{3}{|c|}{$\begin{array}{l}\text { Violent methods } \\
\qquad N=80\end{array}$} & \multicolumn{3}{|c|}{$\begin{array}{l}\text { Self-poisoning } \\
\qquad N=81\end{array}$} & \multirow[b]{2}{*}{$p^{b}$} & \multicolumn{3}{|c|}{$\begin{array}{c}\text { Violent methods } \\
\qquad N=31\end{array}$} & \multicolumn{3}{|c|}{$\begin{array}{l}\text { Self-poisoning } \\
\qquad N=30\end{array}$} & \multirow[b]{2}{*}{$p^{b}$} & & \\
\hline & $n$ & M & $95 \% \mathrm{Cl}$ & $n$ & M & $95 \% \mathrm{Cl}$ & & $n$ & M & $95 \% \mathrm{Cl}$ & $n$ & M & $95 \% \mathrm{Cl}$ & & $\begin{array}{l}\text { Violent } \\
\text { methods }\end{array}$ & $\begin{array}{l}\text { Self- } \\
\text { poisoning }\end{array}$ \\
\hline SIS & 80 & 16.2 & $15.2,17.2$ & 81 & 13.3 & $12.2,14.4$ & $<.001^{\star \star}$ & & & & & & & & & \\
\hline SSI & 37 & 20.1 & $17.9,22.3$ & 32 & 23.1 & $20.6,25.6$ & .07 & & & & & & & & & \\
\hline$\left.S S\right|^{a}$ & 13 & 19.5 & $15.1,24.0$ & 12 & 21.6 & $16.5,26.7$ & $.54^{\mathrm{d}}$ & 9 & $19^{f}$ & $15.2,27.9$ & 8 & $20^{f}$ & $10.4,30.1$ & $.82^{\mathrm{d}}$ & $.24^{\mathrm{e}}$ & $.14^{\mathrm{e}}$ \\
\hline $\mathrm{BDI}$ & 80 & 22.2 & $19.7,25.3$ & 81 & 26.8 & $23.9,29.7$ & $<.05^{\star}$ & & & & & & & & & \\
\hline$\left.\mathrm{BD}\right|^{\mathrm{a}}$ & 31 & 20.5 & $15.3,25.7$ & 30 & 26.1 & $21.0,31.1$ & .12 & 31 & 17.6 & $12.8,22.4$ & 30 & 17.3 & $12.5,22.1$ & .94 & $<.05^{\star}$ & $<.05^{\star}$ \\
\hline BHS & 80 & 10.1 & $8.7,11.4$ & 81 & 11.9 & 10.6, 13.2 & .06 & & & & & & & & & \\
\hline$\underline{B H S}{ }^{a}$ & 31 & 9.1 & $6.6,11.5$ & 30 & 11.8 & $9.9,13.6$ & .08 & 31 & 8.1 & $5.8,10.5$ & 30 & 9.3 & $7.2,11.5$ & .44 & .21 & $<.05^{\star}$ \\
\hline
\end{tabular}

Note. BDI = Beck Depression Inventory, questionnaire; BHS = Beck Hopelessness Scale, questionnaire; SIS = Beck Suicide Intention Scale, interview at

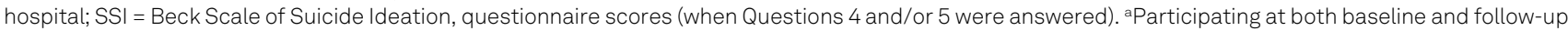
bIndependent-samples $t$ test. "Paired-samples $t$ test. ${ }^{\mathrm{d}}$ Mann-Whitney $U$ test between two independent groups where the data do not meet parametric

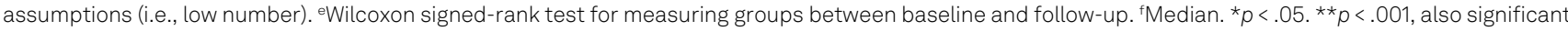
when split in gender between methods (male $<0.05$, female $<0.001$ ).

Therefore, assessments specific to the individual should be central to suicide risk assessment (Chan et al., 2016). However, in the present study, the suicidal ideation score did not decrease significantly over time. Instead, it remained high for both groups, indicating that underlying mental problems are long-lasting and may be associated with poor long-term prognosis for both groups, even though the VM group employed a more lethal method. In addition to demographic differences, also observed in other studies (Giner et al., 2014), there was a difference in patient characteristics in the two groups, and higher suicidal intent at admission was a marker of such a difference. In the current study, the VM group did not score higher than the SP group on suicidal ideation, depression, or hopelessness at any time point, which may indicate a more spontaneous suicide attempt for the VM group. Evaluating impulsivity becomes crucial to the suicide risk assessment (Chan et al., 2016; Suominen et al., 2004).

Suicidal ideation is generally associated with depression (Goldston et al., 2009; Hallgren et al., 2017), but suicidal acts require more than a depressed mood and thoughts of death (Hawton \& van Heeringen, 2009). In the present study, the suicidal ideation score remained high at followup, but the depression score decreased for both groups. Depression is well recognized as a major risk factor for suicide. Our findings may indicate that the combination of high suicidal ideation and high depression represents low risk, even though suicidal ideation is still high. However, depression does not seem to be the only reason for suicidal ideation among patients who attempt suicide. Factors associated with psychosis or difficult life situations might also be involved.
A meta-analysis by Townsend et al. (2001) reported that depression and hopelessness decreased over time for patients in treatment. Although hopelessness did not differ between groups at baseline in the present study, it decreased moderately, but significantly, for the SP group at follow-up. Based on the reported importance of suicidal intent and hopelessness in suicide (Sidley et al., 1999), a higher score was predicted for patients in the VM group. Impulsivity and hopelessness, combined with the lethality of former suicide attempts, are closely linked to the lethality of future suicide attempts (Gvion, 2018). However, the fact that hopelessness did not decrease by the 12 month follow-up and that suicide ideations remained high in VM patients may contribute to a poorer prognosis and explain the high mortality and risk of later death by suicide (Runeson et al., 2010). In accordance with a report by Giner et al. (2014), it seems that patients making medically severe SP attempts (i.e., with complications that warrant hospitalization beyond observation in an emergency room) are more similar to patients in the VM group on admission.

Psychiatric comorbidity has been strongly associated with suicide attempts, as reflected by the increased risk of suicide attempts by people with an increasing number of disorders (Goldston et al., 2009). Major psychiatric disorders have also been found to be associated with increased risk of both suicide attempts over time and a fatal outcome in a subsequent suicide attempt when the index episode involved a VM (Runeson et al., 2010). In the present study, suicidal ideation, depression, and hopelessness did not differ according to psychiatric diagnoses, but the study design and the low numbers of patients examined meant it was not possible to further analyze the role of psychiatric diagnoses. 
Table 3. Suicidal intention, suicidal ideation, depression, and hopelessness within psychiatric diagnosis - baseline and 12-month follow-up $(n=61)$

\begin{tabular}{|c|c|c|c|c|c|}
\hline & \multicolumn{2}{|c|}{ Baseline } & \multicolumn{2}{|c|}{ 12-month follow-up } & \\
\hline$n$ & $M d n$ & $95 \% \mathrm{Cl}$ for $\mathrm{M}$ & $M d n$ & $95 \% \mathrm{Cl}$ for $\mathrm{M}$ & \\
\hline
\end{tabular}

Psychosis (F20-29)

$\begin{array}{ccccccc}\text { SIS } & 6 & 13.5 & 7,17 & & & \\ \text { SSI } & - & - & - & - & - & \text { a } \\ \text { BDI } & 6 & 11.5 & 3,46 & 3 & 1,30 & \text { a } \\ \text { BHS } & 6 & 6.5 & 1,19 & 2.5 & 0,18 & \text { a } \\ \text { Personality disorder } & (F 60-69) \\ \text { SIS } & 14 & 16 & 7,18 & & & \\ \text { SSI } & 7 & 23 & 18,31 & 20.5 & 15,31 & \text { a } \\ \text { BDI } & 14 & 24.5 & 15,47 & 17.5 & 6,31 & <.05^{*} \\ \text { BHS } & 14 & 13.0 & 9,19 & 10.0 & 5,14 & .09\end{array}$

Affective disorder (F30-39)

$\begin{array}{lllllll}\text { SIS } & 26 & 16 & 15,17 & & & \\ \text { SSI } & 6 & 15 & 8,26 & 25 & 5,38 & \text { a } \\ \text { BDI } & 26 & 23.0 & 19,29 & 16 & 8,23 & <.05^{\star} \\ \text { BHS } & 26 & 11 & 8,15 & 6.5 & 4,10 & .13\end{array}$

Substance use disorder (F10-19)

\begin{tabular}{lllllll} 
SIS & 9 & 10 & 7,15 & & & \\
SSI & 3 & 13 & 12,15 & 15.5 & 10,21 & a \\
BDI & 9 & 19 & 8,28 & 19 & 6,33 & a \\
BHS & 9 & 8 & 2,14 & 7 & 3,12 & a \\
\hline
\end{tabular}

Note. $\mathrm{BDI}=$ Beck Depression Inventory, questionnaire; BHS = Beck Hopelessness Scale, questionnaire; SIS = Beck Suicide Intention Scale, interview at hospital; SSI = Beck Scale of Suicide Ideation, questionnaire scores (when questions 4 and/or 5 were answered). The diagnoses are set in a hierarchy with only one diagnosis per patient. ${ }^{a} \mathrm{~T}$ cannot be computed because there are no valid pairs, or the data do not meet parametric assumptions. ${ }^{b}$ Wilcoxon signed rank test for measuring groups between baseline and follow-up. ${ }^{*} p<.05$.

\section{Strengths and Limitations}

The study design was original, as no previous prospective cohort studies comparing suicidal intent, suicidal ideation, depression, and hopelessness between VM and SP groups were found. Furthermore, the current study included a high number of participants for a prospective cohort study with a follow-up of 1 year after baseline of patients using VM. The psychometric instruments were validated and have been used extensively.

Despite the original study design and the relatively high number of VM patients at baseline, the statistical power was weak for analyses of subgroups (i.e., psychiatric diagnoses), and the intended number of patients and gender distribution was not achieved. Although the follow-up response rate was consistent with previous studies of suicidal patients (Grimholt et al., 2015), the low proportion of patients included at follow-up was also a limitation.

\section{Clinical Implications and Future Research}

Patients attempting suicide by both VM and SP scored high for suicidal ideation, with the VM group scoring higher for suicidal intent at baseline. The results for SSI, BDI, and BHS were all higher at baseline for participants missing from the 12-month follow-up, indicating that the results of these analyses might have been even more clinically serious for these patients. Additionally, patients lost to follow-up may have a poorer prognosis, due to their increased inability to remain in treatment. Prediction of later suicide is complicated, but the current data indicate that evaluation of suicidal intent, suicidal ideation, hopelessness, and depression may be helpful in this assessment. Although clinicians emphasize the importance of intent prior to a suicide attempt, it is worth noting that suicidal ideation did not differ between the VM and SP groups. After a suicide attempt, suicidal ideation remained high over time in these groups, and this needs to be considered both for immediate treatment and for long-term follow-up.

\section{Conclusion}

Higher scores for suicidal intent and lower levels of depression in patients using VM, and the lack of difference between patients using VM and SP in suicide ideation and hopelessness, indicate that patients using VM are more spontaneous or perform more determined acts in their suicide attempts. Long-term treatment is recommended for patients who have attempted suicide regardless of the methods used, as suicidal ideation, hopelessness, and depression remain high even after 1 year.

\section{References}

Beautrais, A. L. (2003). Subsequent mortality in medically serious suicide attempts: A 5 year follow-up. Australian \& New Zealand Journal of Psychiatry, 37(5), 595-599. https://doi.org/10.1046/j. 1440-1614.2003.01236.x

Beck, A. T., Steer, R. A., Beck, J. S., \& Newman, C. F. (1993). Hopelessness, depression, suicidal ideation, and clinical diagnosis of depression. Suicide and Life-Threatening Behavior, 23(2), 139-145. https://doi.org/10.1111/j.1943-278x.1993.tb00378.x

Bedrosian, R. C., \& Beck, A. T. (1979). Cognitive aspects of suicidal behavior. Suicide and Life-Threatening Behavior, 9(2), 87-96. https://doi.org/10.1111/j.1943-278X.1979.tb00433.x

Bjornaas, M. A., Hovda, K. E., Heyerdahl, F., Skog, K., Drottning, P., Opdahl, A., Jacobsen, D., \& Ekeberg, O. (2010). Suicidal intention, psychosocial factors and referral to further treatment: A oneyear cross-sectional study of self-poisoning. BMC Psychiatry, 10(1), 58. https://doi.org/10.1186/1471-244X-10-58 
Bjornaas, M. A., Jacobsen, D., Haldorsen, T., \& Ekeberg, O. (2009). Mortality and causes of death after hospital-treated self-poisoning in Oslo: A 20-year follow-up. Clinical Toxicology (Philadelphia), 47(2), 116-123. https://doi.org/10.1080/ 15563650701771981

Chan, M. K. Y., Bhatti, H., Meader, N., Stockton, S., Evans, J., O'Connor, R. C., Kapur, N., \& Kendall, T. (2016). Predicting suicide following self-harm: Systematic review of risk factors and risk scales. British Journal of Psychiatry, 209(4), 277-283. https:// doi.org/10.1192/bjp.bp.115.170050

Cooper, J., Kapur, N., Webb, R., Lawlor, M., Guthrie, E., MackwayJones, K., \& Appleby, L. (2005). Suicide after deliberate self-harm: A 4-year cohort study. American Journal of Psychiatry, 162(2), 297-303. https://doi.org/10.1176/appi.ajp.162.2. 297

Courtet, P. (2018). Risque suicidaire lors du premier épisode psychotique [Suicidal risk during the first psychotic episode]. L'Encephale, 44(6), S39-S43. https://doi.org/10.1016/s00137006(19)30078-8

Giner, L., Jaussent, I., Olié, E., Béziat, S., Guillaume, S., Baca-Garcia, E., Lopez-Castroman, J., \& Courtet, P. (2014). Violent and serious suicide attempters. Journal of Clinical Psychiatry, 75(3), e191-e197. https://doi.org/10.4088/JCP.13m08524

Goldston, D. B., Daniel, S. S., Erkanli, A., Reboussin, B. A., Mayfield, A., Frazier, P. H., \& Treadway, S. L. (2009). Psychiatric diagnoses as contemporaneous risk factors for suicide attempts among adolescents and young adults: Developmental changes. Journal of Consulting and Clinical Psychology, 77(2), 281-290. https://doi. org/10.1037/a0014732

Grimholt, T. K., Jacobsen, D., Haavet, O. R., \& Ekeberg, O. (2017). Lower suicide intention in patients with personality disorders admitted for deliberate self-poisoning than in patients with other diagnoses. Annals of General Psychiatry, 16, 21. https://doi. org/10.1186/s12991-017-0145-3

Grimholt, T. K., Jacobsen, D., Haavet, O. R., Sandvik, L., Jorgensen, T., Norheim, A. B., \& Ekeberg, O. (2015). Structured follow-up by general practitioners after deliberate self-poisoning: A randomised controlled trial. BMC Psychiatry, 15, 245. https://doi.org/ 10.1186/s12888-015-0635-2

Gvion, Y. (2018). Aggression, impulsivity, and their predictive value on medical lethality of suicide attempts: A follow-up study on hospitalized patients. Journal of Affective Disorders, 227, 840-846. https://doi.org/10.1016/j.jad.2017.11.033

Hallgren, K. A., Ries, R. K., Atkins, D. C., Bumgardner, K., \& RoyByrne, P. (2017). Prediction of suicide ideation and attempt among substance-using patients in primary care. Journal of the American Board of Family Medicine, 30(2), 150-160. https://doi. org/10.3122/jabfm.2017.02.160264

Harriss, L., Hawton, K., \& Zahl, D. (2005). Value of measuring suicidal intent in the assessment of people attending hospital following self-poisoning or self-injury. British Journal of Psychiatry, 186(1), 60-66. https://doi.org/10.1192/bjp.186.1.60

Haw, C., Casey, D., Holmes, J., \& Hawton, K. (2015). Suicidal intent and method of self-harm: A large-scale study of self-harm patients presenting to a general hospital. Suicide and Life-Threatening Behavior, 45(6), 732-746. https://doi.org/10.1111/sltb.12168

Hawton, K., Bergen, H., Casey, D., Simkin, S., Palmer, B., Cooper, J., Kapur, N., Horrocks, J., House, A., Lilley, R., Noble, R., \& Owens, D. (2007). Self-harm in England: A tale of three cities. Social Psychiatry and Psychiatric Epidemiology, 42(7), 513-521. https:// doi.org/10.1007/s00127-007-0199-7

Hawton, K., \& van Heeringen, K. (2009). Suicide. Lancet, 373(9672), 1372-1381. https://doi.org/10.1016/S0140-6736(09) 60372-X

Klonsky, E. D., May, A. M., \& Saffer, B. Y. (2016). Suicide, suicide attempts, and suicidal ideation. Annual Review of Clinical
Psychology, 12, 307-330. https://doi.org/10.1146/annurevclinpsy-021815-093204

Nordentoft, M., Mortensen, P. B., \& Pedersen, C. B. (2011). Absolute risk of suicide after first hospital contact in mental disorder. Archives of General Psychiatry, 68(10), 1058-1064. https://doi. org/10.1001/archgenpsychiatry.2011.113

Persett, P. S., Grimholt, T. K., Ekeberg, O., Jacobsen, D., \& Myhren, H. (2018). Patients admitted to hospital after suicide attempt with violent methods compared to patients with deliberate selfpoisoning - a study of background variables, somatic and psychiatric health and suicidal behavior. BMC Psychiatry, 18(1), 21. https://doi.org/10.1186/s12888-018-1602-5

Ramanathan, R., Ramachandran, A. S., Periasamy, K., \& Saminathan, K. (2016). Assessment of suicidal intent. Indian Journal of Psychological Medicine, 38(6), 529-532. https://doi.org/10.4103/ 0253-7176.194907

Runeson, B., Tidemalm, D., Dahlin, M., Lichtenstein, P., \& Langstrom, N. (2010). Method of attempted suicide as predictor of subsequent successful suicide: National long term cohort study. BMJ, 341, c3222. https://doi.org/10.1136/bmj.c3222

Samuelsson, M., Jokinen, J., Nordstrom, A.-L., \& Nordstrom, P. (2006). CSF 5-HIAA, suicide intent and hopelessness in the prediction of early suicide in male high-risk suicide attempters. Acta Psychiatrica Scandinavica, 113(1), 44-47. https://doi.org/10. 1111/j.1600-0447.2005.00639.x

Sidley, G. L., Calam, R., Wells, A., Hughes, T., \& Whitaker, K. (1999). The prediction of parasuicide repetition in a high-risk group. British Journal of Clinical Psychology, 38(Pt 4), 375-386. https:// doi.org/10.1348/014466599162971

Stenbacka, M., \& Jokinen, J. (2015). Violent and non-violent methods of attempted and completed suicide in Swedish young men: The role of early risk factors. BMC Psychiatry, 15, 196. https://doi.org/10.1186/s12888-015-0570-2

Sun, S. H., \& Jia, C. X. (2014). Completed suicide with violent and non-violent methods in rural Shandong, China: A psychological autopsy study. PLoS One, 9(8), e104333. https://doi.org/10.1371/ journal.pone.0104333

Suominen, K., Isometsä, E., Martunnen, M., Ostamo, A., \& Lönnqvist, J. (2004). Health care contacts before and after attempted suicide among adolescent and young adult versus older suicide attempters. Psychological Medicine, 34(2), 313-321. https://doi.org/10.1017/S0033291703008882

Townsend, E., Hawton, K., Altman, D. G., Arensman, E., Gunnell, D., Hazell, P., House, A., \& Van Heeringen, K. (2001). The efficacy of problem-solving treatments after deliberate self-harm: Metaanalysis of randomized controlled trials with respect to depression, hopelessness and improvement in problems. Psychological Medicine, 31(6), 979-988. https://doi.org/10.1017/ s0033291701004238

Witt, K., Daly, C., Arensman, E., Pirkis, J., \& Lubman, D. (2019). Patterns of self-harm methods over time and the association with methods used at repeat episodes of non-fatal self-harm and suicide: A systematic review. Journal of Affective Disorders, 245, 250-264. https://doi.org/10.1016/j. jad.2018.11.001

Woodford, R., Spittal, M. J., Milner, A., McGill, K., Kapur, N., Pirkis, J., Mitchell, A., \& Carter, G. (2019). Accuracy of clinician predictions of future self-harm: A systematic review and metaanalysis of predictive studies. Suicide and Life-Threatening Behavior, 49(1), 23-40. https://doi.org/10.1111/sltb.12395

\section{History}

Received December 10, 2019

Revision received October 14, 2020

Accepted October 26, 2020

Published online April 23, 2021 


\section{Acknowledgments}

The authors want to thank the collaborators from the cooperating hospitals in Norway: Bente Rabba, Innlandet Hospital Trust; Anny Mortensen, University Hospital of Northern Norway (UNN); Trond Jørgensen, Akershus University Hospital (AHUS); Jørn Bøtker, Haukeland University Hospital (HUS); and Andrea Chioqueta, Stavanger University Hospital (SUS). We also wish to thank the staff and the research group at the Department of Acute Medicine, Oslo University Hospital (OUS), for their help in enrolling patients and for providing constructive criticism during the preparation of this manuscript. The study was supported by RVTS-East and Oslo University Hospital.

\section{Conflicts of Interest}

None.

\section{ORCID}

Per Sverre Persett

(D) https://orcid.org/0000-0003-3312-7262

\section{Per Sverre Persett}

Department of Acute Medicine

Oslo University Hospital

Postboks 4950

Nydalen, 0424 Oslo

Norway

uxpese@ous-hf.no
Per Sverre Persett, MS, is a PhD fellow whose main clinical and scientific work is in the treatment and follow-up of hospital admissions with acute self-poisoning and suicidal behavior. His work is also linked to a regional network in suicide prevention work.

Øivind Ekeberg's, MD, PhD, main clinical and scientific work is in suicidal behavior and crisis intervention. He is a member of the board of the IASP and is a recipient of the Erwin Ringel Service Award.

Dag Jacobsen's, MD, PhD, FAACT, main clinical and scientific work is in treating acute self-poisoning - and in the follow-up of these patients. He is also Medical Director of the National Poisons Information Centre in Norway.

Mari Bjørnaas', MD, PhD, main clinical and scientific work is in treating acute self-poisoning, and in the follow-up of suicidal attempt. She is also working at the National Poisons Information Centre in Norway.

Hilde Myhren's, MD, PhD, main clinical and scientific work is in the treatment of acute medical illness and follow-up after intensive care treatment. She is Chief Medical Director at Oslo University Hospital, Norway. 